\author{
부식성 식도염의 지연성 진행에 의한 사망 1 예 \\ 이화여자대학교 의학전문대학원 내과학교실 \\ 김혜인 · 심기남 · 조형원 · 최주영 · 이신아 · 이민진 · 오다연 · 노선희 \\ 태정현 · 김성은 · 정혜경 · 김태헌 · 정성애 · 이선영 · 유 권 · 문일환 \\ $=$ Abstract $=$
}

\title{
A Case of Death Due to Late Progression of Corrosive Esophagitis after Strong Alkali Ingestion
}

\author{
Hye-In Kim · Ki-Nam Shim $\cdot$ Hyoung Won Cho $\cdot$ Ju Young Choi $\cdot$ Shin A Lee $\cdot$ Min Jin Lee \\ Da Yeon Oh · Sun Hee Roh · Chung Hyun Tae $\cdot$ Seong-Eun Kim · Hye-Kyung Jung \\ Tae Hun Kim · Sung-Ae Jung · Sun Young Yi · Kwon Yoo · Il Hwan Moon \\ Department of Internal Medicine, Ewha Womans University College of Medicine
}

\begin{abstract}
Ingestion of corrosive substances can produce severe injury to the gastrointestinal tract and can even result in death in the acute phase. The extent and degree of damage depends on the type and amount of substances. There are occasional reports of severe contiguous injury to the esophagus and stomach caused by strong alkali ingestion in the acute phase. Usually the deaths occur within a couple of days due to multi-organ failure after ingestion of relatively much amount of agent for a suicidal attempt. But death due to late progression is very rare.

We have reported a case of 60-year-old female patient who was diagnosed as corrosive esophagitis after accidental ingestion of strong alkali. Initial endoscopic findings were compatible with IIa-IIa-0(according to Zargar's classification) in the esophagus, stomach and duodenum, respectively. After several weeks of supportive care, her subjective symptoms were much improved during she had been wating for the operation of colon interposition due to esophageal stricture. Metabolic acidosis and thrombocytopenia developed abruptly probably due to upper gastrointestinal tract necrosis and she died when 60 days had passed after the occurrence of initial esophageal injury.
\end{abstract}

KEY WORDS : Corrosive esophagitis · Alkali ingestion · Esophageal necrosis.

\section{서 론}

부식제에 의한 상부 위장관 손상은 자살 목적이나 부
주의에 의한 부식제 섭취로 빈번하게 발생하며 남녀에 서 고르게 나타난다. 부식제 섭취 후 점막의 손상 정도 는 부식제의 양, 종류, 형태, 접촉시간, 농도 등에 의존 한다 ${ }^{1)}$. 부식성 식도 손상에서 흔한 초기 합병증에는 구 
강 점막과 인두의 화상, 흥통, 연하 곤란, 타액 분비 항 진, 구역 및 구토가 있다. 후두부 부종으로 호흡 곤란도 발생 가능하다 ${ }^{2}$. 일부 환자에서는 알칼리 섭취 8 12일 후에 수혈을 요하는 토혈과 흑색변이 발생할 수 있다 ${ }^{3)}$. 부식제에 의한 후기 합병증으로는 3 개월에서 1년 사이 에 나타날 수 있는 식도 협착, 수 년 후에도 일어날 수 있는 위유문부 협착증 등이 있다 ${ }^{4)}$. 식도 협착의 발생은 초기 식도 손상 정도 및 위 손상 정도와 상관 관계가 있 는 것으로 되어 있다. 식도 협착 발생의 위험 요인으로 식도의 손상 정도, 침범된 식도의 범위 등을 들고 있다 ${ }^{5)}$. 부식제에 의한 사망은 섭취 초기에 주로 발생하며 식 도, 위, 십이지장에서 IIIb-IIIb-IIIa 이상의 손상을 입 고 섭취 후 짧은 시간 내에 다기관 부전으로 사망한 환 자의 보고가 있다 ${ }^{6)}$. 다른 연구에서도 초기에 Grade III 이상의 손상을 받은 환자에서 출혈, 천공, 누루 형성 등 의 주요 부작용이 주로 2 주 이내에 발생하는 것으로 보 고하고 있다 ${ }^{3)}$. 저자들은 부주의에 의해 강알칼리를 마 신 후 초기에 내시경 검사에서 식도, 위, 십이지장의 점 막에서 IIa-IIa-0 정도로 다른 연구에 비해 경한 손상 을 보였던 환자가 발생 9 주째에 부식성 손상에 의한 지 연성 상부 위장관 괴사로 진행되어 사망한 예를 경험하 였기에 보고하는 바이다.

\section{증 례}

환 자 : 60 세 여자.

주 소 : 강알칼리 화공 약품을 삼킨 후 발생한 인후 통증.

현병력 : 환자는 내원 당일 실수로 강알칼리 화공 약 품 약 $30 \mathrm{cc}$ 를 마시고 뱉은 후, 인후부 통증이 발생하여 응급실 진료 후에 본원 소화기 내과에 입원하였다.

과거력 : 당뇨를 진단 받아 경구 투약 중이었고, 천식 은 특별한 치료를 받지 않고 안정된 상태였다. 정신 질 환 병력은 없었으며, 자궁 근종으로 자궁 절제술을 시 행 받았다.

가족력 : 특이 사항 없음.

이학적 소견 : 입원 시 활력 증후는 혈압 $180 / 100$ $\mathrm{mm} \mathrm{Hg}$, 호흡수 24 회/분, 맥박 88 회/분, 체온 $37^{\circ} \mathrm{C}$ 였 다. 의식은 명료하였으며 심계항진, 호흡곤란 등의 증 상은 호소하지 않았다. 심음 청진상 심잡음을 동반하지 않은 규칙적인 심음이 청진되었으며 호흡음 청진과 복
부 진찰에서 특이한 소견은 없었다. 입안 점막과 혀, 인 두, 후두에도 특이 소견 없었다.

검사실 소견 : 내원 당시 말초 혈액 검사에서 백혈구 $11,900 / \mathrm{mm}^{3}$, 혈색소 $11.7 \mathrm{~g} / \mathrm{dL}$, 혈소판 $227,000 / \mathrm{mm}^{3}$ 이었다. 혈청 생화학 검사에서 총단백 $6.0 \mathrm{~g} / \mathrm{dL}$, 알부 민 $3.5 \mathrm{~g} / \mathrm{dL}$, AST $22 \mathrm{IU} / \mathrm{L}$, ALT $20 \mathrm{IU} / \mathrm{L}$, alkaline phosphatase $274 \mathrm{IU} / \mathrm{L}$, 총빌리루빈 $0.6 \mathrm{mg} / \mathrm{dL}$, 아밀 라아제 $65 \mathrm{U} / \mathrm{L}$, 리파아제 $57 \mathrm{U} / \mathrm{L}, \mathrm{CK} 56 \mathrm{IU} / \mathrm{L}, \mathrm{CK}-$ MB $2.4 \mathrm{ng} / \mathrm{mL}$, Troponin T $0.010 \mathrm{ng} / \mathrm{mL}$ 미만, $\mathrm{LD}$ $281 \mathrm{IU} / \mathrm{L}$, 나트륨 $140 \mathrm{mEq} / \mathrm{L}$, 칼륨 $3.8 \mathrm{mEq} / \mathrm{L}$, 칼슘 $8.4 \mathrm{mg} / \mathrm{dL}$, 혈당 $218 \mathrm{mg} / \mathrm{dL}, \mathrm{BUN} 17 \mathrm{mg} / \mathrm{dL}$, 크레아 티닌 $0.8 \mathrm{mg} / \mathrm{dL}, \mathrm{CRP} 9.02 \mathrm{mg} / \mathrm{dL}$ 였다. 단순 소변 검 사에서 당 $3+$, 케톤 \pm 이었다. 심전도는 정상이었다.

방사선학적 소견 : 단순 흉부 및 복부 엑스선에서는 특이 소견 없었다.

위내시경 소견 : 내원 당일에 시행한 상부위장관내시 경에서 인후두의 점막은 정상적으로 보존되어 있었다. 상부 식도에서부터 얕은 궤양이 관찰되었고 이는 흰색 의 가성점막으로 덮여 있었다. 또한 점막의 발적 및 부 종이 보였으며 점막의 취약성이 동반되어 있었다. 위에 서도 심한 부종과 발적 및 표재성 궤양이 관찰되었고 이는 위의 체부까지 지속되었다(Fig. 1). 십이지장에는 이상 소견 없었다.

치료 및 경과 : 입원 1주 후 내시경을 다시 시행하였 고 중부식도부터 식도-위 접합부에 이르기까지 표재성 궤양과 함께 흰색의 삼출물이 덮혀 있었으나 협착은 발 견되지 않았다(Fig. 2A). 위에서도 두터운 삼출물로 덮 여 있는 궤양이 발견되었으며 부종 소견이 있었다. 입 원 4주 후 시행한 내시경에서 절치로부터 $27 \mathrm{~cm}$ 지점 의 식도에서부터 협착이 있었고, $30 \mathrm{~cm}$ 부터는 심한 협

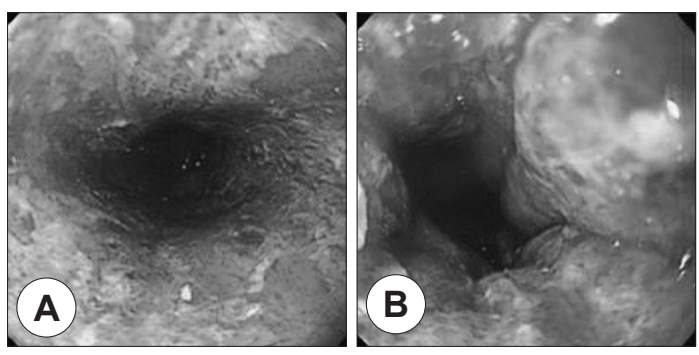

Fig. 1. Initial endoscopic findings. A : Shallow ulcers covered with whitish exudates were seen through total esophagus. Friability, hyperemia and edema of mucosa were noticed. B : Superficial ulceration, erosion and hemorrhage of mucosa was seen in the stomach. 
착으로 더 이상 진입할 수 없었다(Fig. $2 \mathrm{~B}$ ). 환자는 비 경구 영양 공급을 유지하면서 심와부의 통증은 진통제 를 사용하여 조절하였다. 환자의 부식제 섭취 4 주 후 시행한 바륨 식도 조영술에서 길이가 $10 \mathrm{~cm}$ 정도 되는 식도 협착이 관찰되었다(Fig. 3). 이는 확장술의 적응 증이 되지 않아 부식제 섭취 9주째에 식도절제술 후 결 장간치술(Colon interposition)을 시행할 계획으로 보 존적인 치료를 유지하였다. 환자의 심와부 통증은 감소 하여 진통제의 용량을 줄이는 도중 식도 점막 손상 60 일째에 급작스러운 혈압 저하와 함께 혈소판 감소증, 대사성 산증을 보였다. 당시 시행한 심초음파에서 심근 의 전측부에서 경도의 운동성 저하 소견을 보였으나 수 축력은 정상범위로 유지되었고, 혈압 저하에 의한 이차
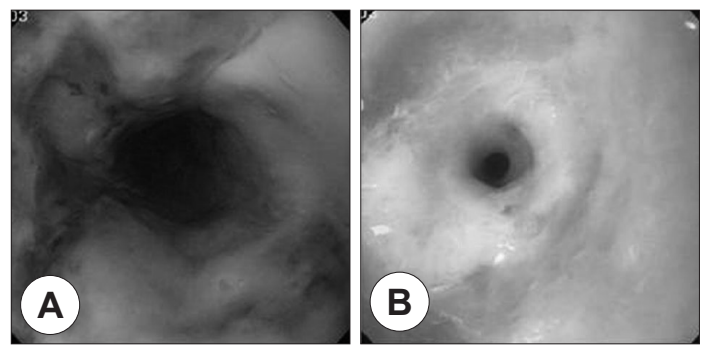

Fig. 2. Follow up endoscopic findings. A : After 7 days, diffuse circular ulcer and hyperemic mucosa covered with whitish exudates were seen at the entire esophagus. B : After 26 days, severe esophageal narrowing was seen at the distal esophagus. So the endoscopic scope could not passed.

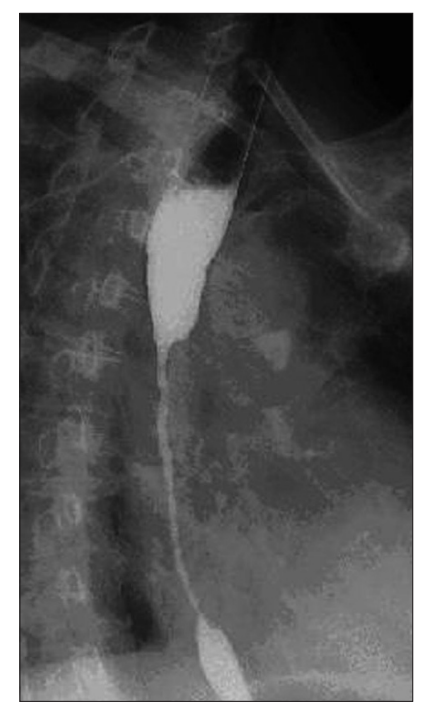

Fig. 3. On the baruim esophagography, esophageal stricture was seen from the midesophagus to distal esophagus.
적인 심근의 손상에 의한 변화로 판정하였다. 복부 전 산화단층촬영에서 장관 출혈이나 위를 포함한 하부 장 관의 천공이 의심되는 소견은 없었다. 혈액학적 이상을 교정하기 위한 혈압상승제, 수혈 등의 치료를 지속하였 으나 대사성 산증이 진행되어 사망하였다.

\section{고 찰}

부식제 섭취 후 점막의 손상 정도는 부식제의 양, 종 류, 형태, 접촉 시간, 농도 등에 의해 결정된다. 알칼리 손상의 대표적인 물질인 수산화 나트륨의 경우 $22.5 \%$ 와 $30 \%$ 의 수산화 나트륨이 식도에 각각 10초, 1 초간 접촉 할 때, 식도 전층의 손상을 줄 수 있다 ${ }^{4)}$. 부식성 손상 초 기 단계에서는 액화 괴사가 일어난다. 단백질과 콜라겐 을 용해시키고 에스테르의 가수분해를 통해 작은 혈관 에서 혈전이 형성되고, 위산과 강알칼리의 중화 반응으 로 발열 반응이 일어난다. 특히 조직 손상은 초기 수 분 동안에 빠르게 진행되고, 이후 수일에 걸쳐 박테리아 감 염, 염증 반응, 육아 조직 형성으로 인한 점막 탈락이 발생한다 ${ }^{7)}$.

알칼리 부식제는 위에서는 위산 분비에 의한 중화 작 용이 일어나 식도에만 손상을 미치는 것으로 알려져 있 었다이). 그러나 알칼리 부식제의 경우는 무향, 무취인 경우가 많아 섭취시에도 부식제임을 인식하지 못하고 상당량을 마실 수 있기 때문에 실제로는 식도뿐만 아니 라 위에도 손상을 줄 수 있단). 과거에 알칼리 부식제 가 식도에 주로 손상을 입힌다는 개념은 이전 자료들에 서 상부 위장관 손상 여부에 결정적으로 영향을 주는 알칼리의 종류, 농도, 섭취량에 대한 언급이 적었기 때 문이며, 급성기에 위내시경이 아닌 식도경으로 검사했 기 때문이기도 하다 ${ }^{899}$. 실제로 음주 상태에서나 자살 목 적으로 다량의 고농도 알칼리를 섭취했을 때는 $93.5 \%$ 에서 급성 위 손상이 관찰되었고 $32.3 \%$ 에서 지연성 위 손상이 관찰되었다 ${ }^{3)}$.

식도염은 알칼리 섭취를 한 모든 환자에서 관찰되는 데 하부식도에서 가장 많이 관찰되고 협착은 $45.2 \%$ 에 서 관찰되었다. 식도, 위와 비교해서 상대적으로 십이지 장은 보존되는데 이는 알칼리가 분문부에 닿았을 때 일 어나는 유문부의 수축에 의한 보호작용에 의해서이다 ${ }^{3)}$.

환자가 호소하는 불편감 정도로 식도, 위 손상의 존재 여부, 부위, 범위를 예측할 수는 없다 ${ }^{10)}$. 구인두 손상과 
상부위장관 손상 사이에 상관 관계가 없음이 널리 알려 져 있다 ${ }^{8)}$. 위내시경의 초기 소견이 정확한 위장관 점막 의 손상 및 환자의 예후 및 치료를 결정하는데 결정적 이며11), 주의해서 위내시경을 시행했을 때 검사에 따르 는 합병증 발생률은 낮다. 내시경에서 초기 점막 손상 정도가 IIb이거나 III인 환자는 누공, 천공, 출혈, 사망 등의 급성 합병증이 발생할 수 있기 때문에 입원하여 경과 관찰하는 것이 필요하다 ${ }^{3)}$.

본 증례의 경우 초기 내시경 소견이 IIa로 식도에 얕 은 궤양과 삼출물이 있었고 위에서 역시 점막의 부종과 궤양 및 미만성 출혈 소견을 보이는 IIa의 부식성 손상 을 보였다. 일반적으로 부식성 손상의 치료는 비경구 영 양법등의 보존적 치료를 시행하는 것으로 되어 있고, 장 막층까지 광범위하고 융합하는 양상의 반점이 있거나 탈색이 있으면 일반적으로 6 8주 후 광범위 절제를 한 다. 이번 증례의 환자는 보존적 치료를 유지하면서 시 행한 내시경 및 식도 바륨 조영에서 $10 \mathrm{~cm}$ 길이의 식도 의 심한 협착을 보여 식도 손상 9 주에 결장간치술을 계 획하고 있었다. 그러나 환자는 천공, 위출혈 등의 급성 기 합병증이 없이 증상이 호전 되던 중에, 임상적으로 식도 괴사가 급속도로 진행되며 치료에도 교정되지 않 는 혈소판 감소증, 대사성 산증이 진행되어 발병 60 일 째에 사망하였다. 한 연구에서는 초기 내시경 소견만으 로 전층에 걸친 괴사가 있는지의 여부는 분별하기 어려 움을 언급하였고, 내시경 소견과 신체 진찰에서 심한 괴사가 없는 환자에게 실제로 전층에 걸친 괴사가 일어 나 사망한 사례를 보고하고 있다 ${ }^{212)}$. Kirsh 등은 내시 경 소견과 실제 식도 손상 소견이 정확히 일치하지 않기 때문에 부식제 섭취 후 내시경 소견에서 하부식도와 위 의 손상이 있을 경우 식도 전체의 손상으로 간주할 것을 강조하였다 ${ }^{13)}$. 내시경에서 IIa를 넘는 식도의 손상이 있 을 경우 식도 내 스텐트를 삽입하여 손상 부위에 일정 한 압력을 가함으로써 예방적인 확장법을 3 주정도 시 행하는 등 적극적으로 대처할 것을 권유하기도 하며, 초 기 내시경에서 전층 괴사가 있는 경우 바로 식도 절제술 을 하기도 한다 ${ }^{214)}$. 본 증례의 환자는 알칼리를 섭취한 후 60 일이 경과하여 지연성 손상이 발생하였다. 이전 연구에도 알칼리에 의한 지연성 손상이 보고된 바가 있 는데, 소아 환자에서 알칼리 섭취 1 3달 후에 치명적 인 상부성문 협착이 발생하여 수술적 방법으로 기도를 확보했던 사례가 있었다 ${ }^{15)}$.
결론적으로 부식제 섭취 초기에 상부위장관 내시경 을 통해 위장관 손상 정도를 평가하여 위장관 협착, 출 혈, 사망 등의 합병증과 예후를 판단하고, 급성기가 지 난 이후에도 염증 반응이 지속되어 지연성 손상을 유발 할 수 있다는 것을 염두 해야 한다. 또한 전층의 식도 괴 사를 추정할 수 있는 증거들이 있는 경우 초기의 적극 적 수술적 치료를 고려할 때 부식제 손상에 의한 후기 합병증 발생, 사망률을 감소 시킬 수 있다. 초기 및 지 연성 부식성 위장관 손상에 대한 표준화된 치료 계획을 세우기 위해서는 앞으로 더 많은 수의 환자를 대상으로 한 대규모 연구가 이루어져야 할 것이다.

\section{요 약}

저자들은 부주의에 의해 강알칼리를 마신 후 초기에 내시경 검사에서 식도, 위, 십이지장의 점막에서 $\mathrm{IIa}-$ IIa-0 정도의 손상을 보였던 환자가, 발생 9주째에 부 식성 손상에 의한 상부 위장관 괴사로 진행되어 사망한 예를 경험하였기에 이에 대해 보고하는 바이다.

중심 단어 : 부식성 식도염 · 알칼리 · 식도 괴사도.

\section{References}

1) Cello JP, Fogel RP, Boland CR : Liquid caustic ingestion : spectrum of injury. Arch Intern Med 1980; 140 : 501-504

2) Aaron E, Wayne T, Lawrence JM, Melvin RP : Corrosive burns of the esophagus and stomach : A recommendation for an aggressive surgical approach. Ann Thorac Surg 1986 ; 41 : 276-283

3) Showkat AZ, Rakesh K, Birender N, Saroj M, Satish Kumar M : Ingestion of strong corrosive alkalis : Spectrum of injury to upper gastrointestinal tract and natural history. Am J Gastroenterol 1992 ; 87 : 337-341

4) Gumaste VV, Dave PB : Ingestion of corrosive substances by adults. Am J Gastroenterol 1992 ; 87 : 1-5

5) Nunes AC, Romaozinho JM, Pontes JM, Rodrigues V, Ferreira M, Gomes D, et al : Risk factors for stricture development after caustic ingestion. Hepatogastroenterology $2002 ; 49: 1563-1566$

6) 염혜정 · 심기남 · 김성은 - 이창배 - 이종수 · 조유경 등 : 부식제로 인한 상부 위장관 손상의 임상양상 및 예후인자. 대한내과학회지 2006; 70:371-377 
7) Kovil R, Vivek V, Gumaste : Corrosive ingestion in adults. J Clin Gastroenterol 2003 ; 37 : 119-124

8) Wijburg FA, Beukers MM, Heymans HS : Nasogastric intubation as sole treatment of caustic esophageal lesions. Ann Otol Rhinol Laryngol 1985 ; 94 : 337-341

9) Symbas PN, Vlasis SE, Hatcher CR : Esophagitis secondary to ingestion of caustic material. Ann Thorac Surg $1983 ; 36: 73-77$

10) Zargar SA, Kochhar R, Nagi B : Ingestion of corrosive acids : Spectrum of injury to upper gastrointestinal tract and natural history. Gastroenterology 1989 ; 97 : 702-707

11) Tucker JA, Yarington CT : The treatment of caustic ingestion. Otolaryngol Clin North Am 1979 ; 12 : 343-350
12) Ray JF, Myers WO, Lawton BR : The natural history of liquid lye ingestion. Arch Surg 1974 ; 109 : 436-439

13) Kirsh MM, Peterson A, Brown JW, Orringer MB, Ritter F, Sloan H : Treatment of caustic injuries of the esophagus. Ann Surg 1978 ; 188 : 675-678

14) Larson DL, Abston S, Evans EB, Dobrkovsky M, Linares HA : Techniques for decreasing scar formation and contractures in the burned patient. J Trauma 1971 ; $11: 807-823$

15) Chen YW, Lai SH, Fang TJ, Li HY, Lee TJ : Pediatric dyspnea caused by supraglottic stenosis : a rare complication of alkali corrosive injury. Eur Arch Otorhinolaryngol $2006 ; 263: 210-214$ 